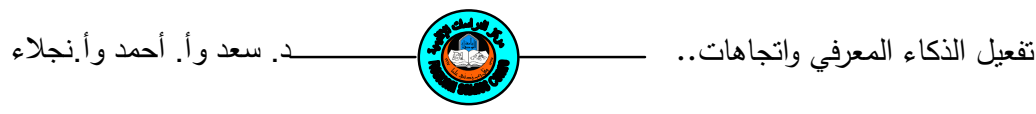

تفعيل الأكاء المعرفي واتجاهات التعليم الاككتروني

ل تلدول مختارة

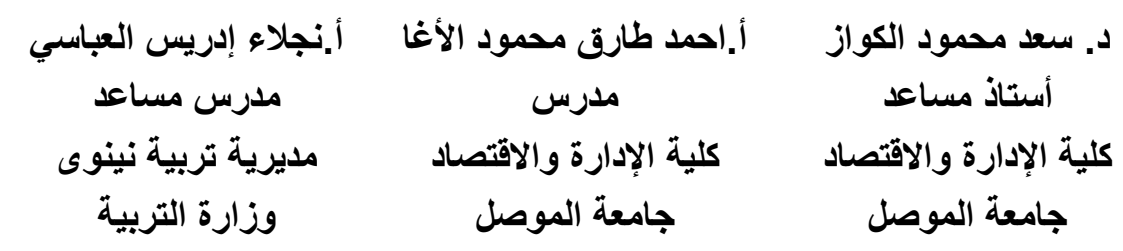

مستخلص البحث

إن التوجه العالمي نحو اقتصاديات المعرفة التي تعتمد بشكل أساس على التقتيات

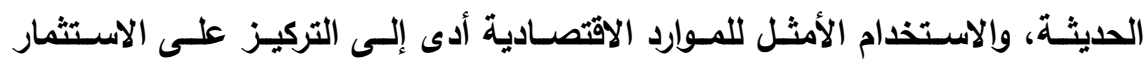

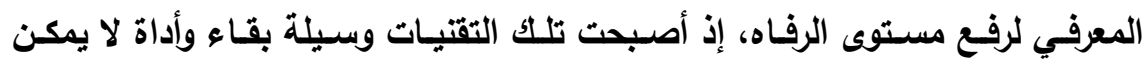

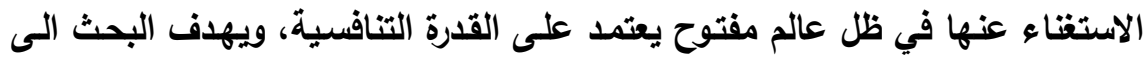

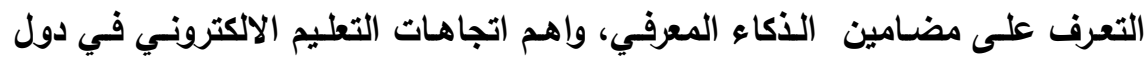

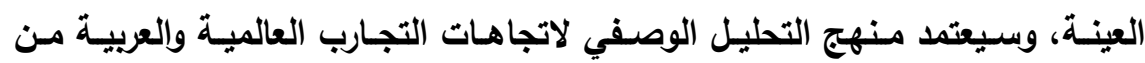

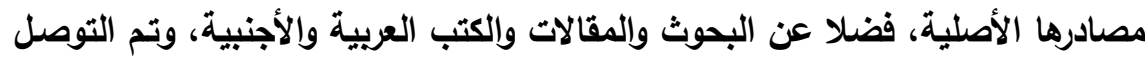

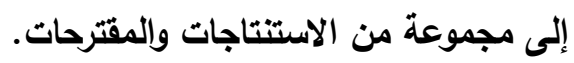

المقدمة

يعـد نهايـة عقد التسـعينات مـن القـرن العشـرين ومطلـع القـرن الحـادي

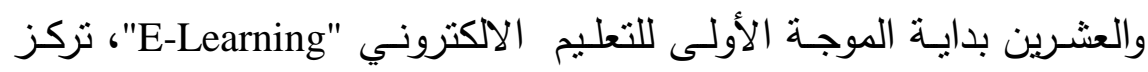

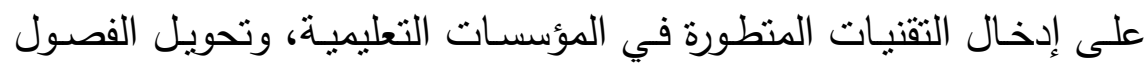
التقليديـة إلى فصـول افتراضية Virtual Classrooms باسـتخدام الثبكات

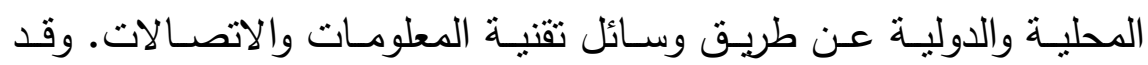
انتشرت مصطلحاته وهي: التعلم على الخط Online Learning، والتعلم 
عبر الثبكة Web based Learning، والتعلم الرقمي Digitally Learning، والتعلم عبر مؤتمرات الفيديو لVideo Conferences.... وغيرها.

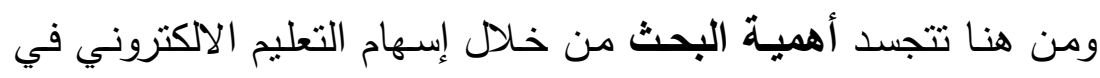
تفعيل الذكاء المعرفي وضمن مسوغاته النظرية واهم التجارب العالمية في هذا المجال.

ويهدف البحث إلى التعرف على الإطلار النظري للتعليم الالكتروني، فضلا عن عرض أهم التجارب العالمية والعربية التي تعد مؤشرات أساسية الإسية التئية لتطبيق الذكاء المعرفي. أما مشكلة البحث فتتلخص بالإجابة عن التساؤل الآتي: ما هو الدور الذي يمارسه التعليم الالكتروني في دعم منظومة الذكاء المعرفي من خلال

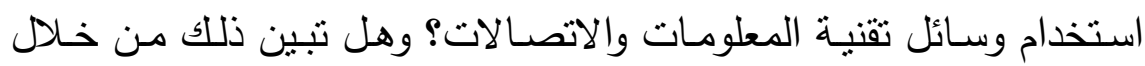
تطبيقه ضمن التجارب العالمية والعربية؟

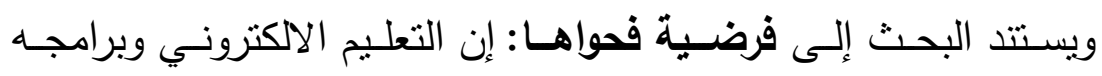

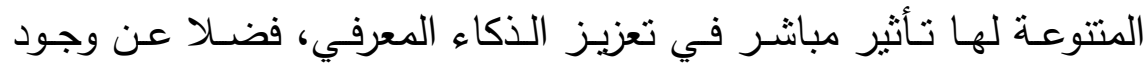
الاختلاف بينه وبين التعليم التقليدي، واءن تطوير مثل هذه البرامج ستدعم العملية التعليمية. وتضمن البحث محورين أساسبين، تتاول الأول الإطار النظري للذكاء

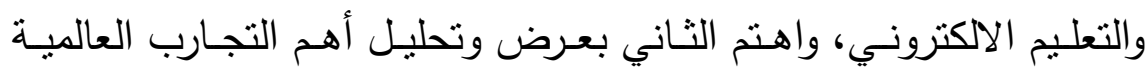

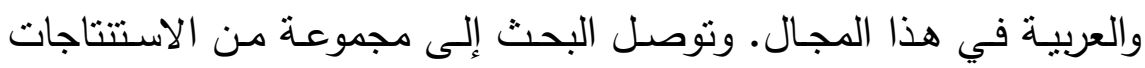
والمقترحات. 


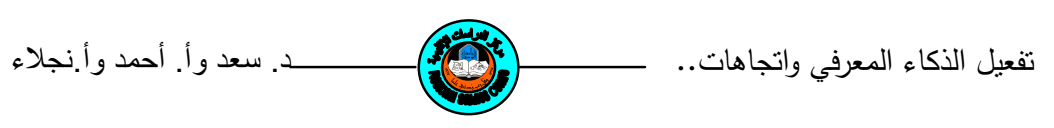

المحور الأول: الإطار النظري للأكاء والتعليم الاكتروني

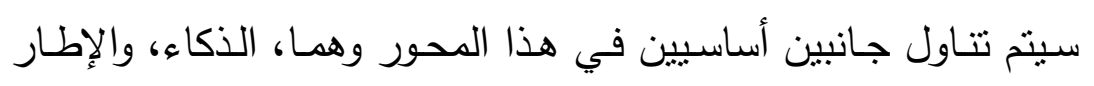

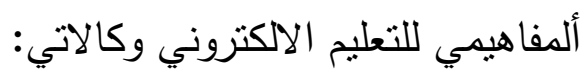

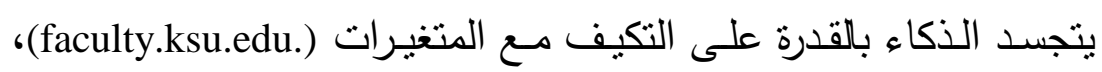

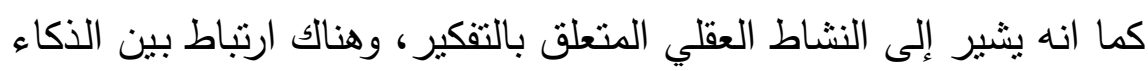

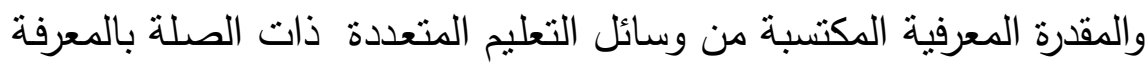

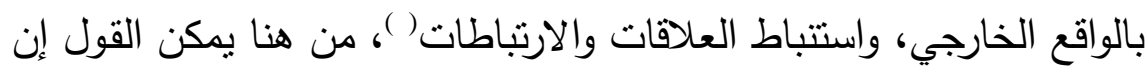

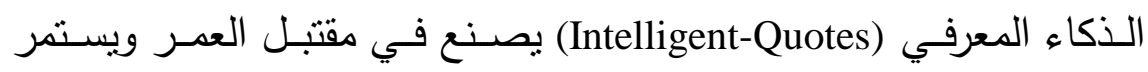

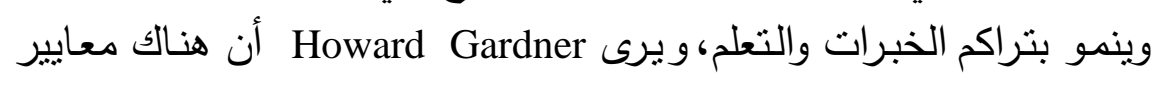

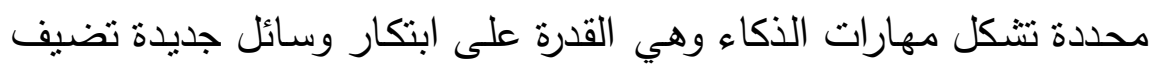

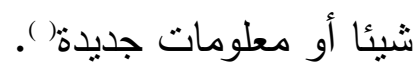

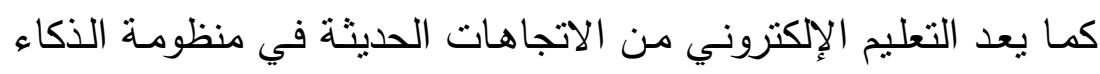

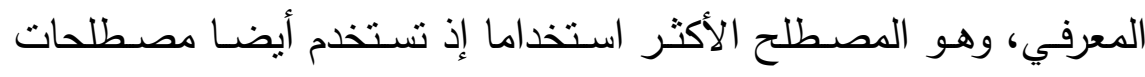

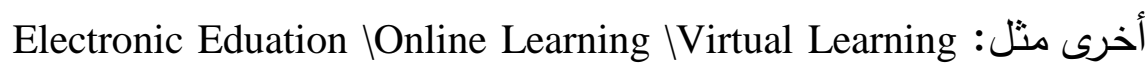
IWeb Based Education

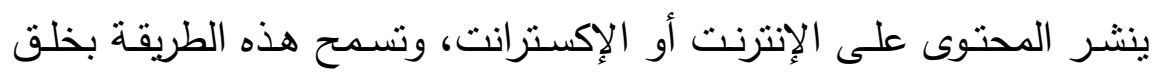

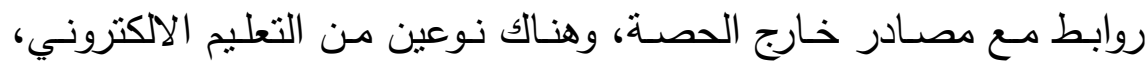

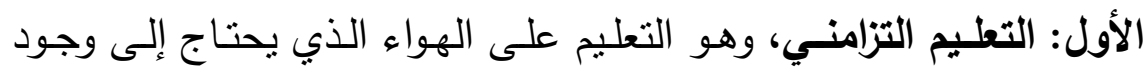

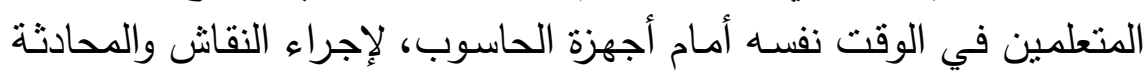

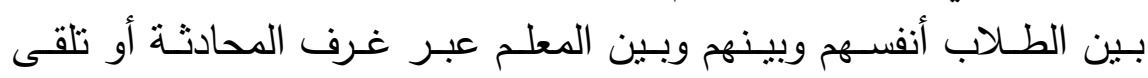

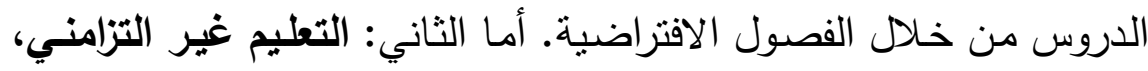

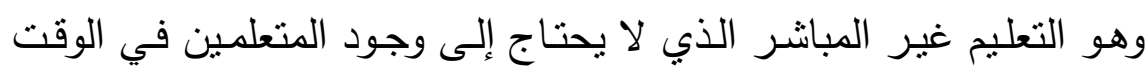

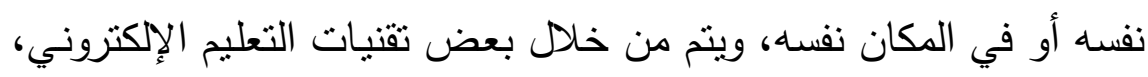


اذ يتم تبادل المعلومات بين الطلاب أنفسهم وبينهم وبين المعلم في أوقات

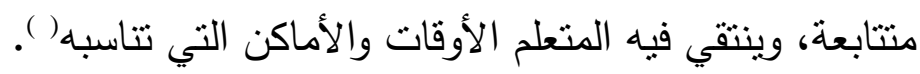

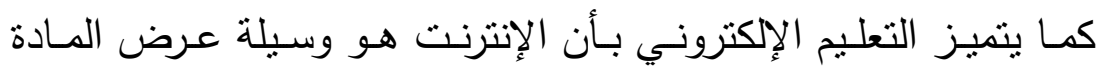

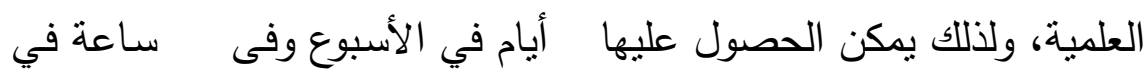

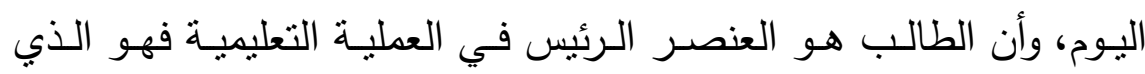
يستطيع تحديد طريقة تعلمه، وأنه يمكن استخدام أساليب تعليم مختلفة مثل:

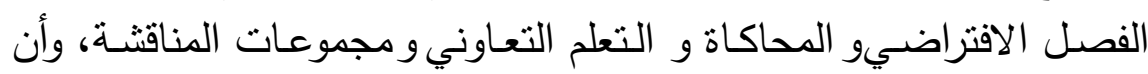
التعليم الإككتروني يتبع خطوات التعليم التقليدي مثل الدراسـة والاختبـارات

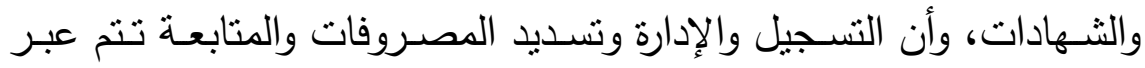
الإنترنت.

كما انه يمثل إيجاد بيئة تفاعلية غنية بالتطبيقات المعتمدة على تقنيات

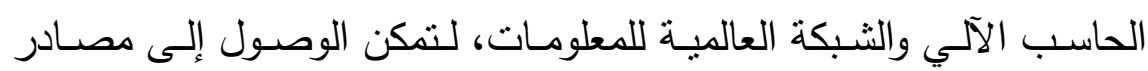

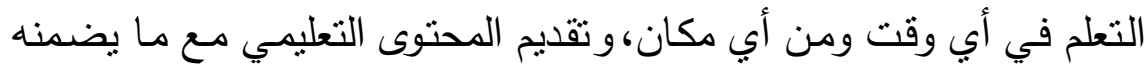

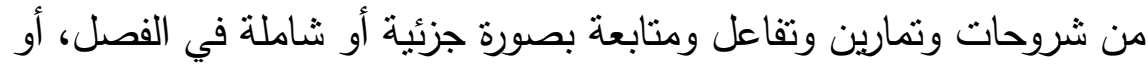

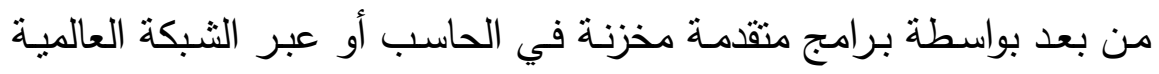

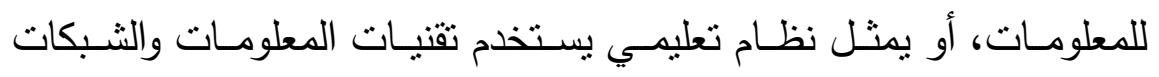
الالكترونية في تدعيم العملية التعليمية من خلال مجموعة من الوسائل منها:

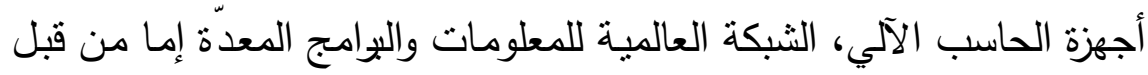

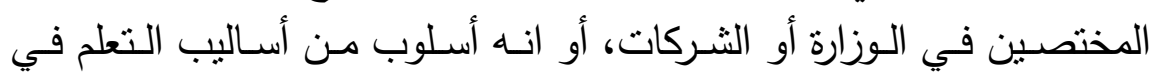

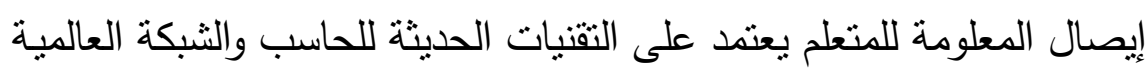

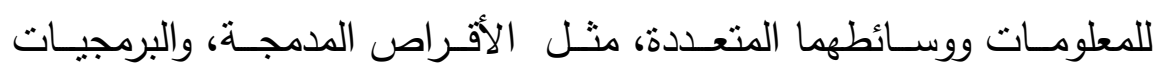

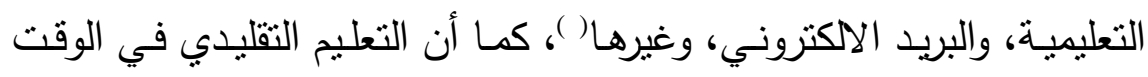
الراهن لم يضف الجديد على المحتوى التعليمي لمواكبة التطورات المعاصرة،

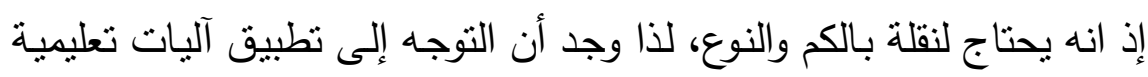
مساندة للتعليم التقليدي كالتعليم الإلكتروني لها القدرة على تحسين الجين الجودة. 
د. سعد وأ. أحمد و أ.نجلاء

وبالإمكـان عـرض جـدول توضـيحي للمقارنـة بينهمـا لمعرفـة تميـز التعليم

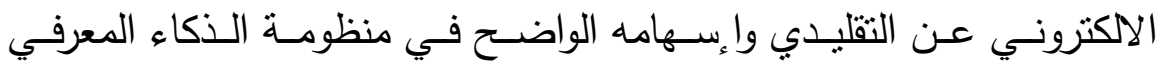
وكالآتي: ( )

\begin{tabular}{|c|c|}
\hline 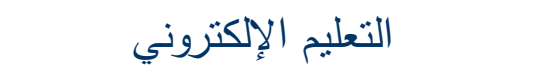 & التعليم التقليدي \\
\hline الطالب محور عملية التعلم & المعلم محور عملية التعليم \\
\hline تتشيط العديد من الحواس & تتشيط حاسة واحدة \\
\hline التقدم في عدة اتجاهات & التقدم في اتجاه واحد \\
\hline وسائط متعددة & وسبط واحد \\
\hline تبادل المعلومات & إلقاء المعلومات \\
\hline التعلم قائم على الإيجابية والاكتشاف & التعلم السلبي \\
\hline الاستجابة تفاعلية ومخطط لها & استجابة المتعلم قائمة على رد \\
\hline 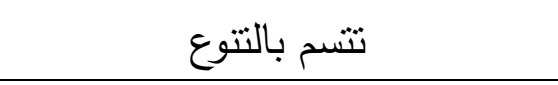 & ت ت تسم بالنمطية \\
\hline 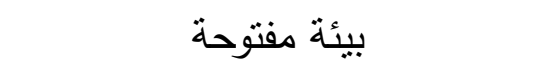 & بيئة مغلقة \\
\hline التعليم تزامني وغير تزامني & التعليم في الوقت نفسه والمكان \\
\hline مصادر متعددة ومنتوعة للمعرفة & المعلم والكتاب مصادر المعرفة \\
\hline التقوبم كمي ونوعي & التقويم غالباً كمي \\
\hline 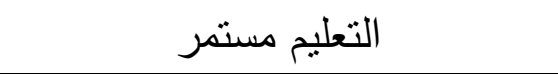 & 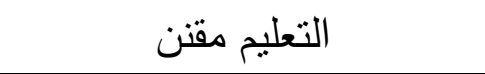 \\
\hline إدارة تعليمية لامركزية & إدارة تعليمية مركزية \\
\hline
\end{tabular}


ويمكن القول بان التعليم الالكتروني هو منظومة لتقديم البرامج التعليمية

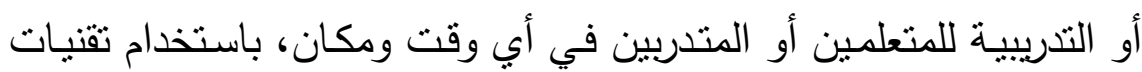

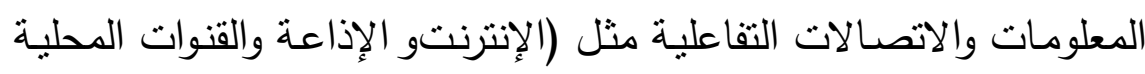

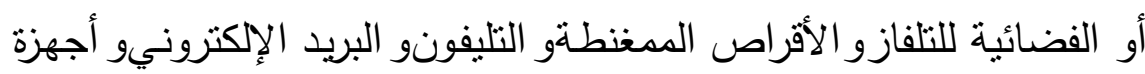

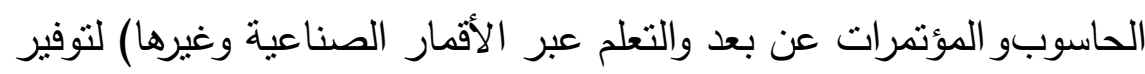

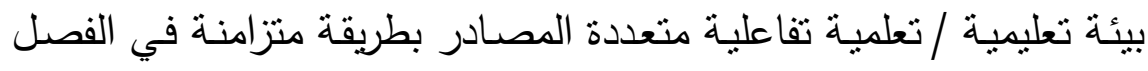

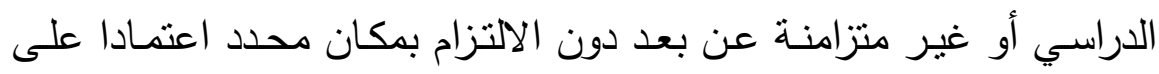

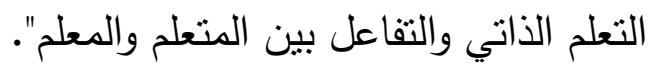

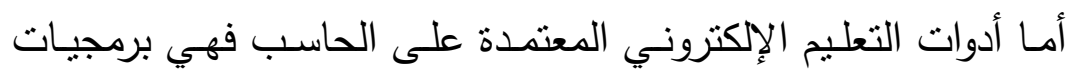

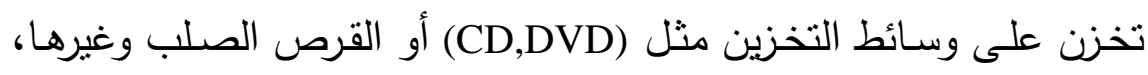

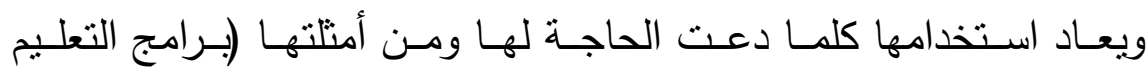

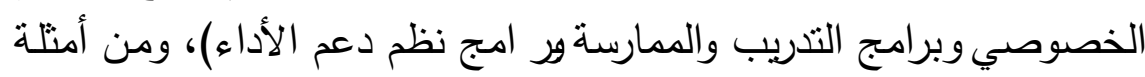

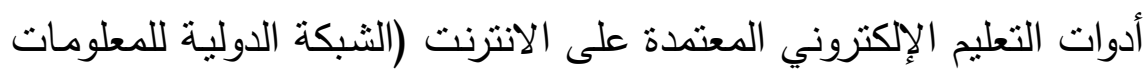

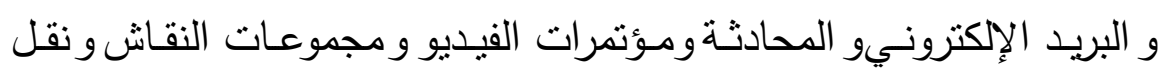
الملفاتو السبورة التفاعلية). كما إن من أحدث مستجدات التقنية في مجال التعليم الإلكتروني، تشمل التهل

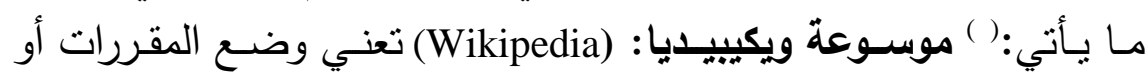

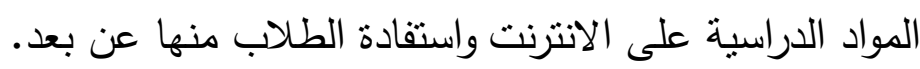

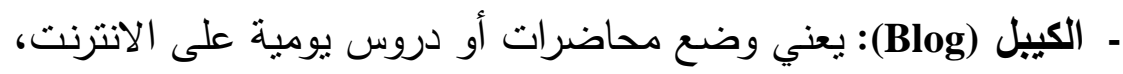

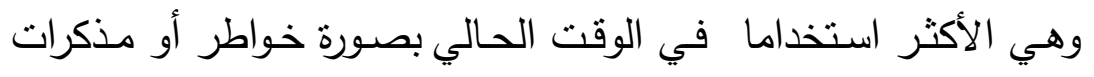
- البرود كاست (Broad Cast): هي تسجيل الهحاضرات ووضعها على الجي

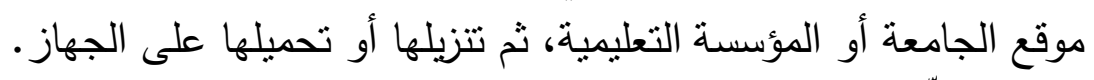

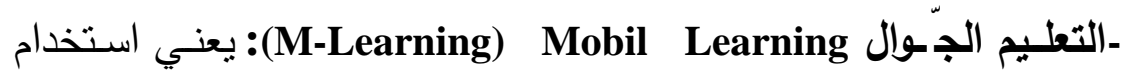

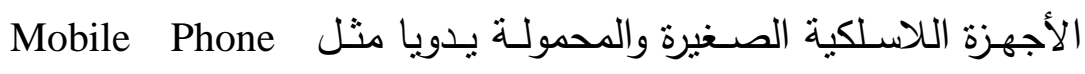




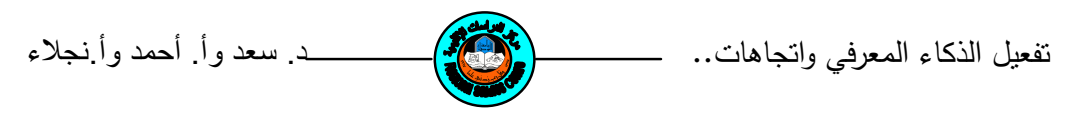

Smart phones PDAs في عمليتي التدريس والتعلم في أي وقت

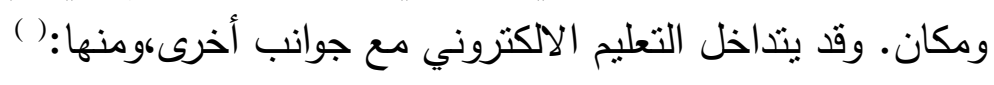

• ثقنية التعليم. Education Technology: تعرفها منظمة اليونسكو بأنها

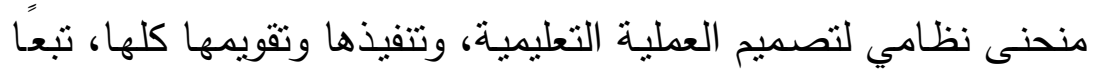
لأهداف محددة، نابعة من نتائج الأبحاث في مجال التعليم، مستخدمة

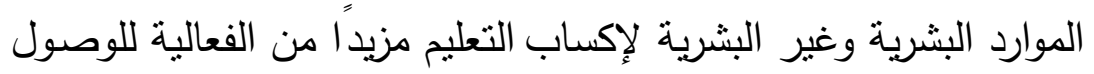
إلى تعلم أفضل.

ث ثقتيـة المعلومـات Technology Information: تعني ثورة المعلومات

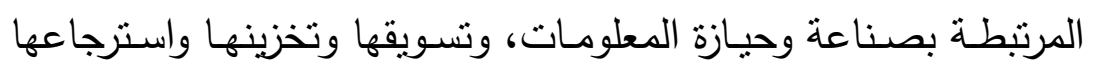

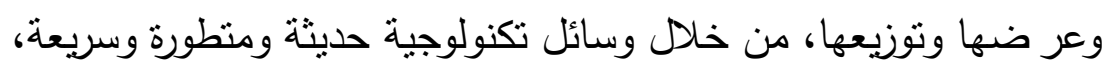
بالاستخدام المشترك للحاسبات الإلكترونيـة ونظم الاتصـالات الحديثة.

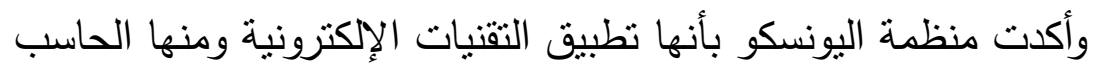

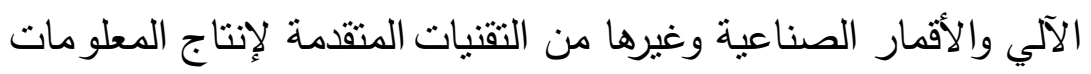

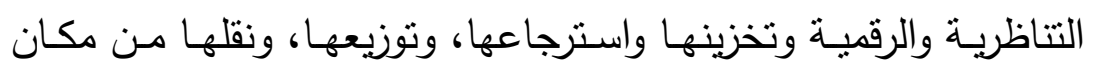

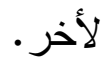

• الوبسائل التعليميـة Educational Tools: وهـي أجهزة وأدوات ومـواد يوظفها المعلم في إطار العملية التعليمية لتحسين عملية التعليم والتعلم، وتشتمل على قنوات الاتصال التي يمكن للمعلم عن طريقها نقل الرسالة بأقل جهد وأقصر وقت وبأوضح ما يمكن وبأقل تكلفة ممكنة.

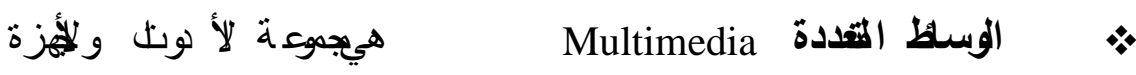
و البرمجيات التي يمكن من خلالها الدمج بين النص و الصورة و الصـوت حول مفاهيم موضـوعية محددة. و التي يمكن استخدامها لغرض فئر إنتاج المواد التعليهة بنماذج مختلفة مما يثري الطر ائق المستخدمة في عرض وض ودي المادة التعليمية المطلوبة. 
• التعليم الالكتروني. Electronic Learning هو نظام تفاعلي يعتمد على بيئة الكترونية منكاملة، ويستهدف بنـاء المقررات الدراسية بطريقة يسهل توصيلها، بواسطة الثبكات الإلكترونية، وبالاعتمـاد على البرامج والتطبيقات التي توفر بيئة مثالية لدمج النص بالصورة والصوت، وتقدم

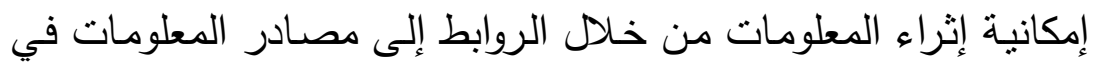
مواقع مختلفة.

أما أهم خصائص برامج التعليم الالكتروني، فهي تشمل الآتي:( ) ( ) > تقديم المحتوى الرقمي للمقررات الدراسية في بيئة متعددة الوسائط.

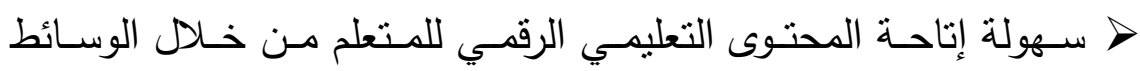
المعتمدة على الحاسوب وشبكاته. > مرونة التحديث المستمر للمقررات الدراسية مع إمكانية مواكبة التطورات إنتئه العلمية الحديثة دون كلف إضافية.

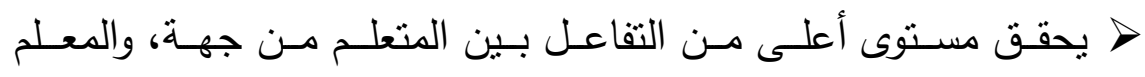
والمحتوى، والزمـلاء، والمؤسسة التعليمية، والبرامج والتطبيقات من جهة لهن ثانية. > تتيح برامج التعليم الاككتروني إمكانية الوصول إليها والإفادة منها دون

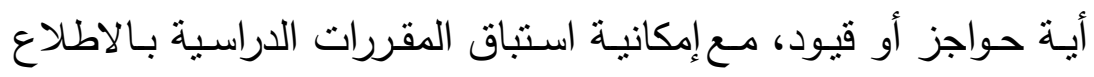

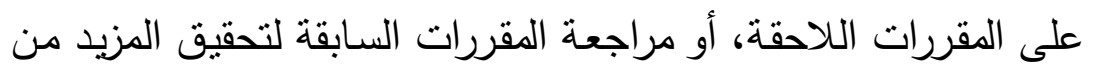
المعرفة، وتمكن المتعلم من تقويم نفسه بشكل مستمر بتتفيذ الاختبارات المباشرة لقياس مستوى التعلم. وهناك خصائص أخرى للتعليم الالكتروني منها: تفاعل الطالب مـع الأستاذ

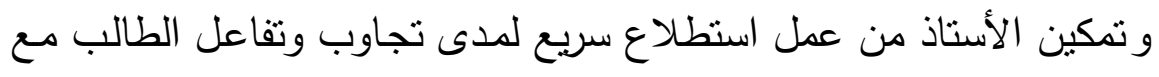
نقاط الدرس المختلفة، فضلا عن عمل تقويم فوري لمدى تجاوب الطلبة مـع

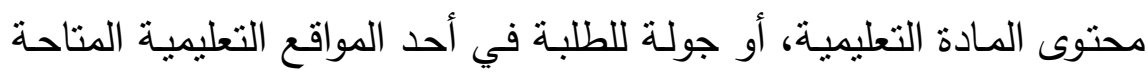




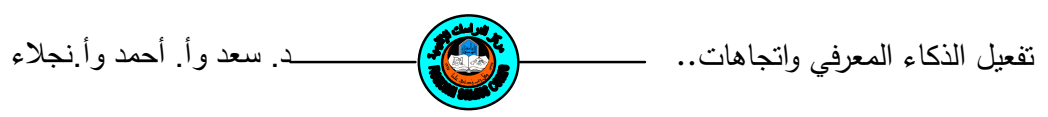

على الانترنت ومساعدتهم على تقسيمه إلى مجموعات في غرف تفاعلية بالصوت والصورة من أجل عمل التجارب.

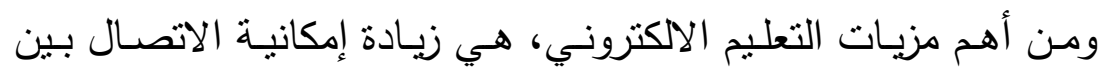

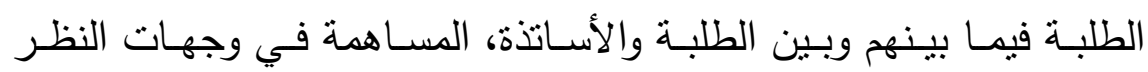

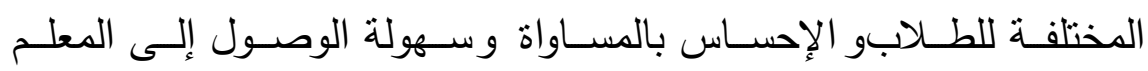

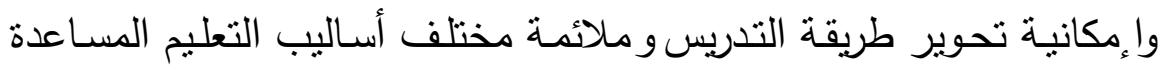

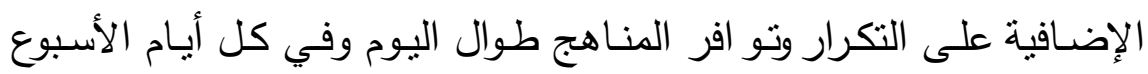

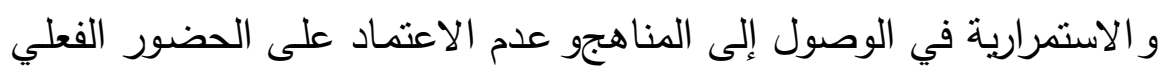
والاستفادة القصوى من الزمن. ومن الجدير ذكره إن التعليم الالكترونيكغير من طر التهن ائق التعليم الأخرى

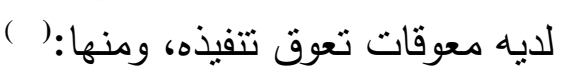

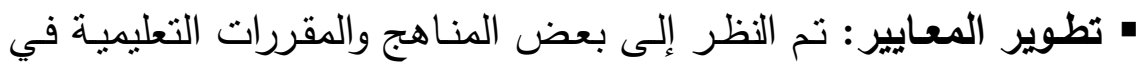

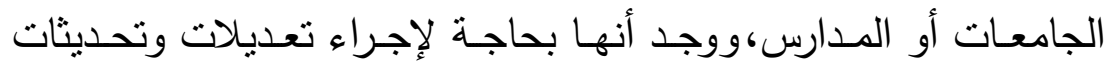

كثيرة نتيجة للتطورات المختلفة كل سنة.

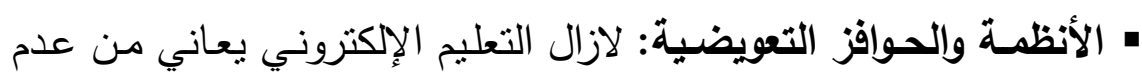

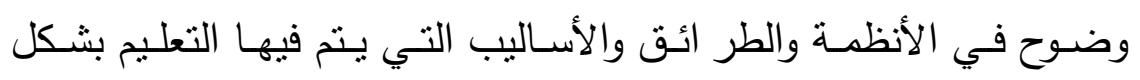

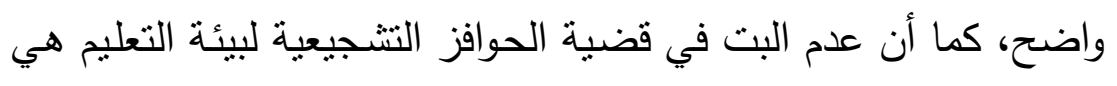
إحدى العقبات الني تعوق فعالية التعليم الإلكتروني.

\section{- نواقص البيئة التعليمية، ومنها}

- نقص الدعم والتعاون المقدم من أجل طبيعة التعليم الفعالة. - نقص المعايير لوضع وتشغيل برنامج فعال ومستقل. - نقص الحوافز لنطوير المحتويات. 
- الخصوصية واللسرية: إن الهجمات على المواقع الرئيسة في الإنترنت، أثرت في المعلمين والتربويين ووضعت الثينة في أذهانهم العديد من الأسئلة

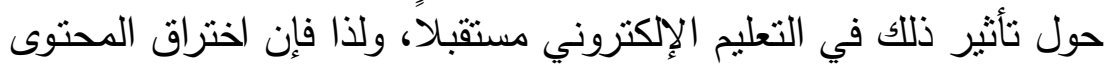

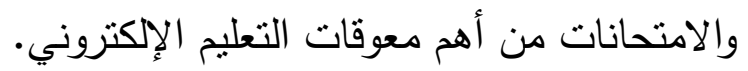

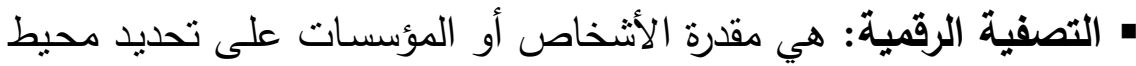

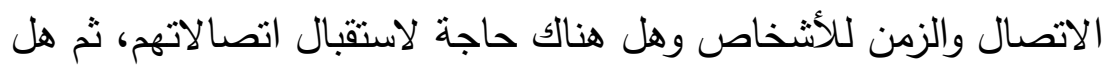

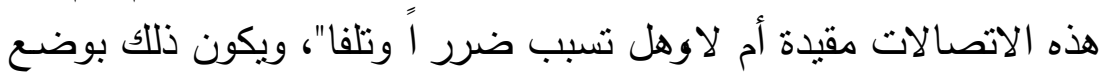

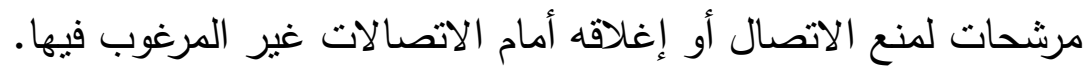

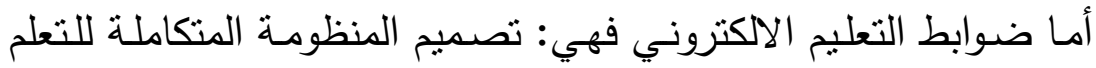

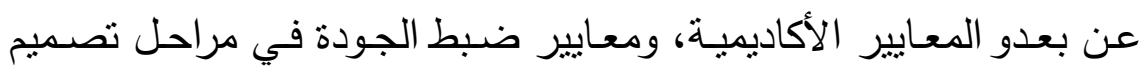
البرامج واعتمادها ومراجعتهاو تطوير ودعم وتقو يم الطلاب ( ) .

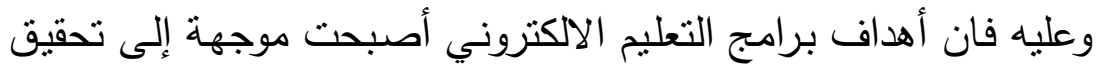

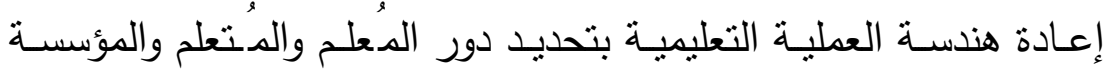

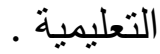
\# استخدام وسائط التعليم الإكتروني في ربط وتفاعل المنظومة التعليمية

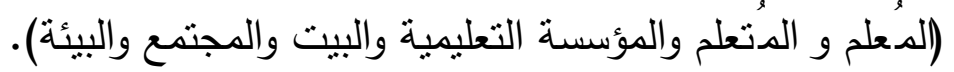
\$ ت تبادل الخبرات التربوية من خلال وسائط التعليم الإكتروني.

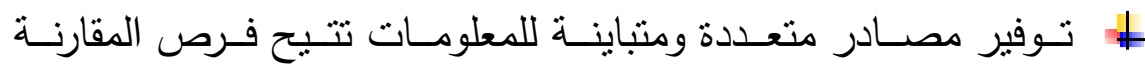
والمناقثنة والتحليل و التقويم.

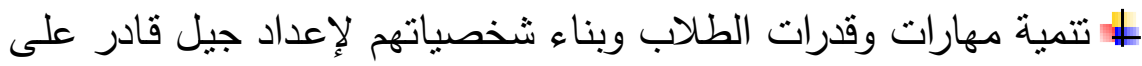

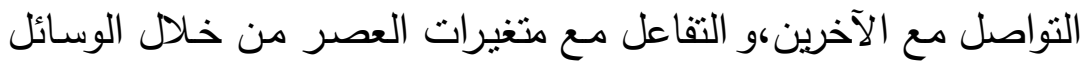

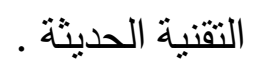

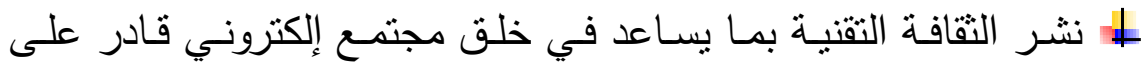

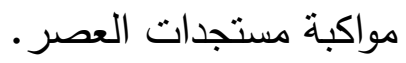




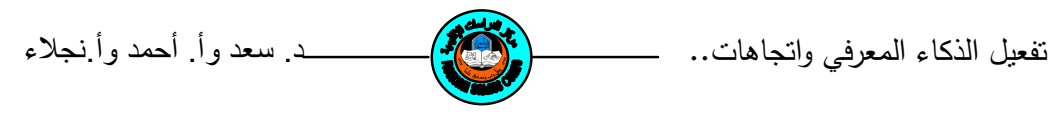

\# تحسين مستوى فاعلية المعلمين وزيادة الخبرة لديهم في إعداد المواد

التعليمية.

+ا الوصول إلى مصادر المعلومات والحصول على الصور والفيليو وأوراق

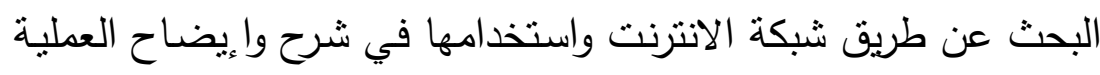

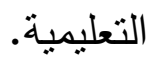

\# توفير المادة التعليمية بصورتها الإكترونية للطالب والمعلم. \#

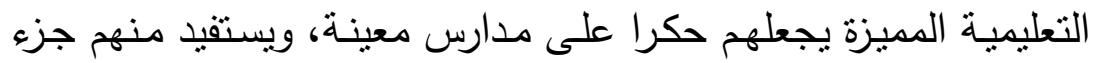
محدود من الطلاب. كما يمكن تعويض النقص في الملاكات الأكاديمية

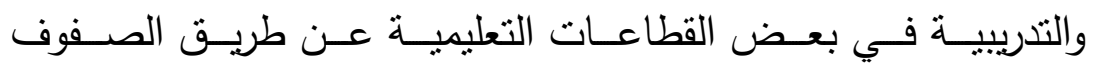
الافتراضية. \# تنـاعد الطالب على الفهم والتعمق أكثر بالدرس إذ بستطيع الرجوع

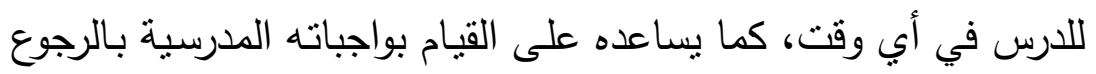

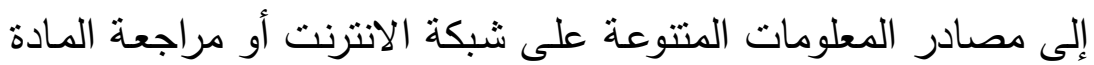

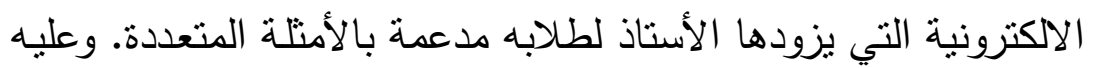

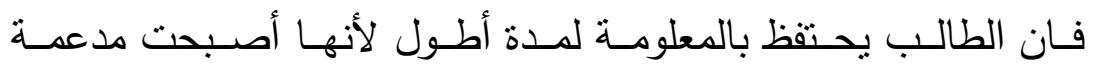
بالصوت والصورة والفهم.

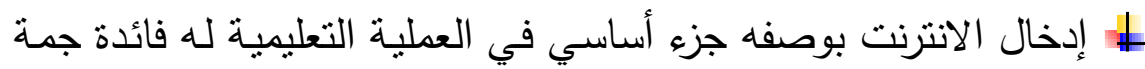

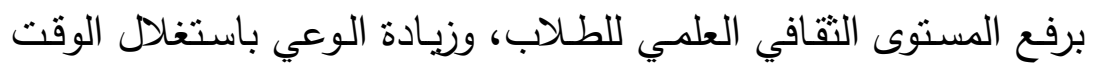

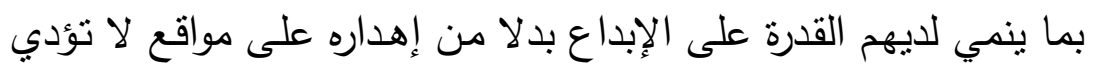
إلا إلى انخفاض المستوى العلمي والثقافي. لإنيا.

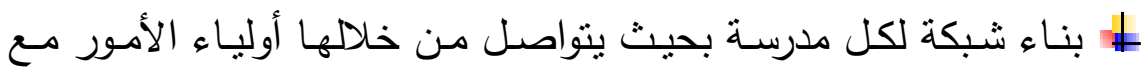
المعلمين والإدارة لكي يكونوا على اضطلاع دائم على على مستوى أبناءهم ونشاطات المدرسة. 
\# تواصـل المدرســة مــع المؤسسـات الثربويـة والحكوميـة بطريقـة منظمـة

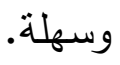
أمـا أهم المعـايير العالميـة لتطـوير بـرامج التعليم الالكترونسي فتــمل

(Sharable Content Object Reference Model) (Scorm) معايير والتي تعني الأنموذج المرجعي لمشاركة المحتوى والأهداف، وهي

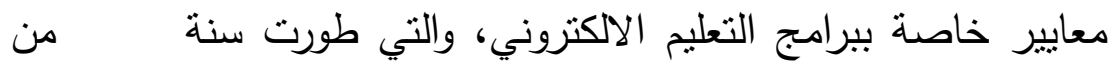

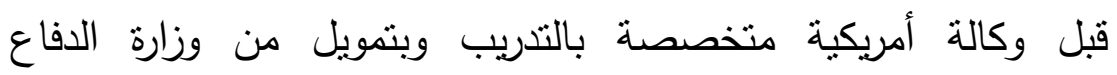
الأمريكية، بهدف تخفيض نفقات التدريب وتوظيف التقنيات الحديثة.

IMS معيار -

Global Consortium for Instructional Management System

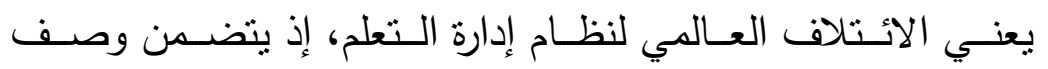

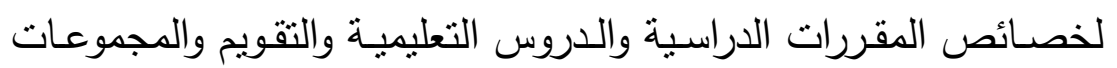

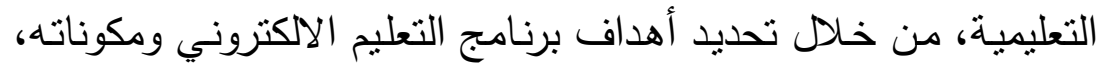
ومصادره.

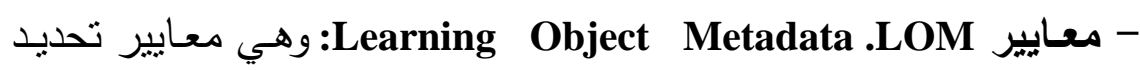
البيانات الفوقية للوحدات التعليمية، وتهدف إلى تمكين المعلمين والطلاب البعاب

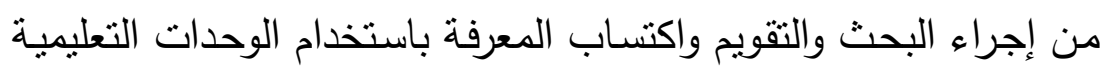

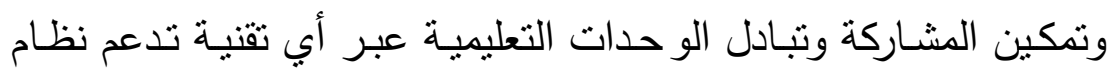

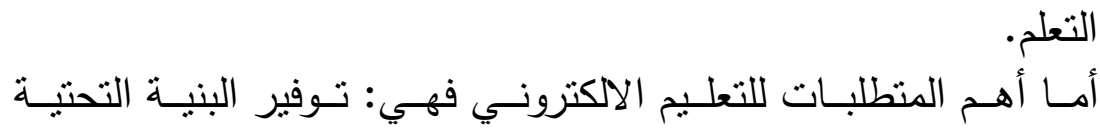

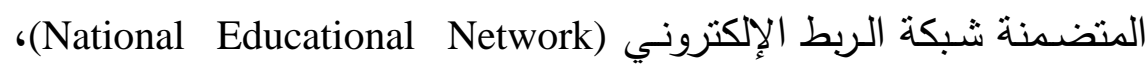

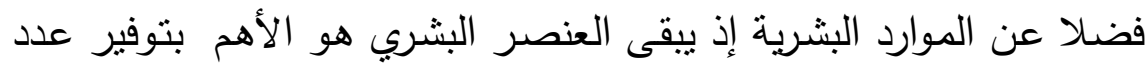

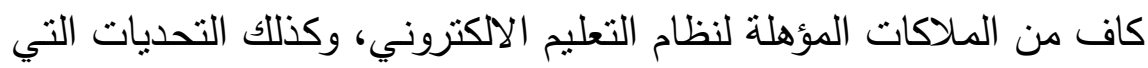

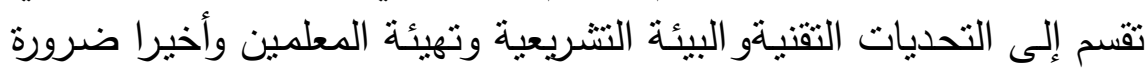


تـو افر التمويـل إذ أن الاسـتشمار المبـدئي لإنشــاء شـبكة المعرفـة وتجهيـز

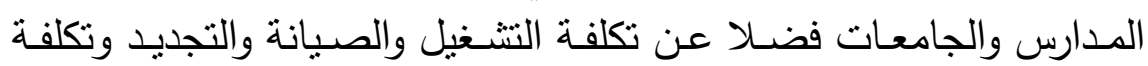
إنتاج المحتويات اللازمة للعملية التعليمية وغيرها تشكل تحديا حقيقيا لأنها

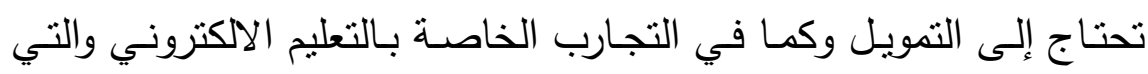
سيتم التطرق إليها في المحور الثاني ( النيل

المحور الثاني: عرض وتحليل لتجارب تطبيق التعليم الالكتروني للدول مختارة

سينم عرض أهم التجارب العالمية والعربية للتعليم الالكتروني، والتي تعد مؤشرات أساسية لتطبيق الذكاء المعرفي، ومناهج عمل تتميز بإعداد خطط وبرامج تعليمية في اتجاه هذا النمط من التعليم، وهي كالأتي ( ) ( ).

\section{أولا: تجريـة الولايات المتحدة الأمريكية}

تبين إن من مدارس التعليم الابتدائي والثانوي في الولايات المتحدة

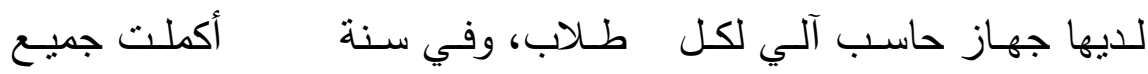
الولايات الأمريكية خططها لتطبيقات الحاسب في مجال التعليم. وبدأت في ولي

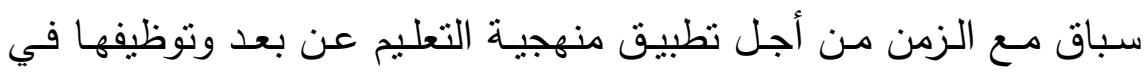
مدارسها، واهتمت بعملية تدريب المعلمين وتوفير البنية التحتية من أجهزة حاسب آلي وشبكات تربط المدارس مع بعضها فضلا وند عن برمجيات تعليمية

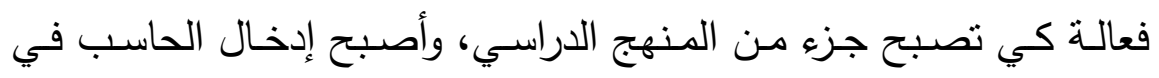
التعليم وتطبيقاته كأساس في المناهج التعليمية كافة.

\section{ثانيا: برنامج كاليفورنيا للتعلم عن بعد}

\section{(California Distance Learning Program)}

يعد من برامج التعلم الافتراضي، إذ يعرض برنامجا عن التعليم الإبداعي

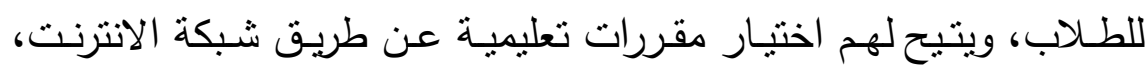


ويسـى هذا البرنـامج للاعتراف بالاهتمامـات المختلفة للطـلاب، وأنمـاط

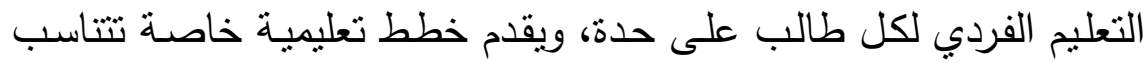

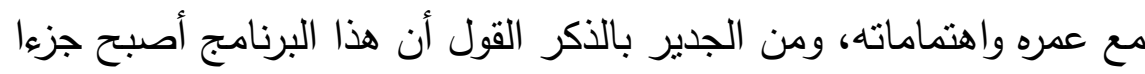
أساسيا من نظام الددارس العامة في ولاية كاليفورنيا.

ثالثا: تجربة اليابان

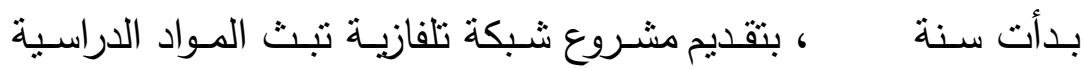

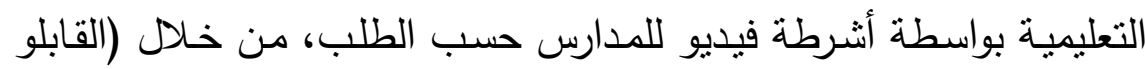

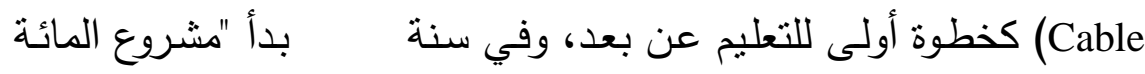

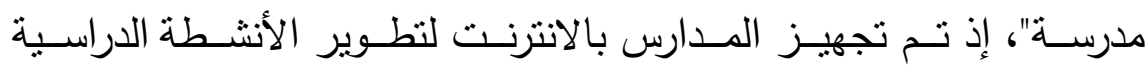

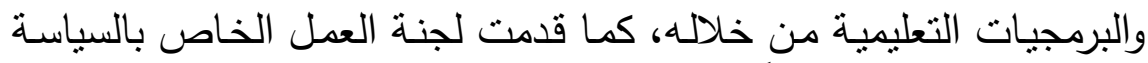

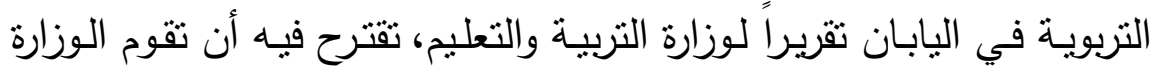

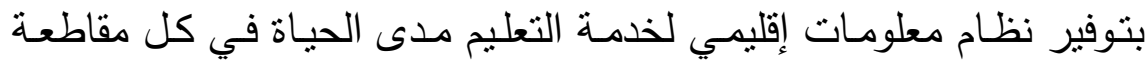

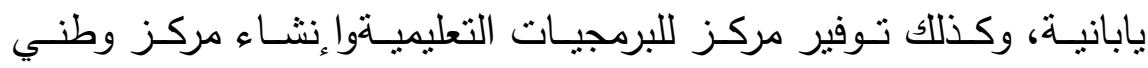

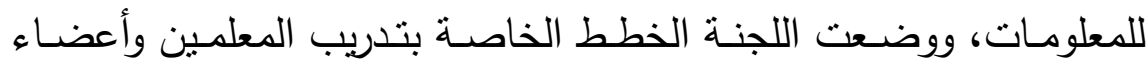

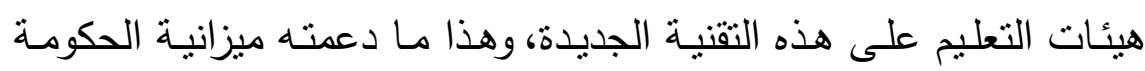

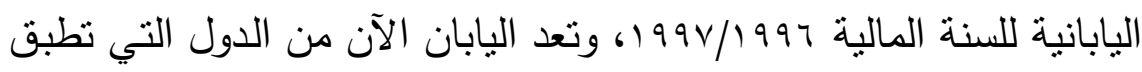

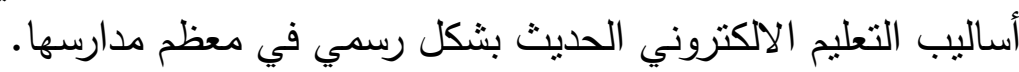
رابعا: التجرية الماليزية التئية

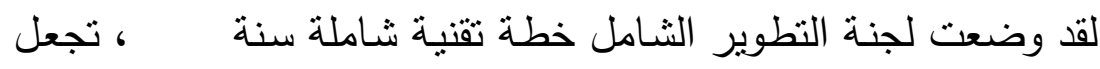

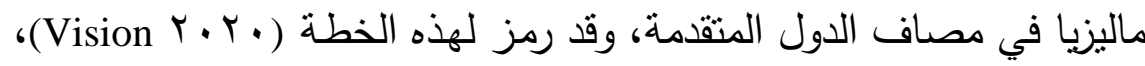

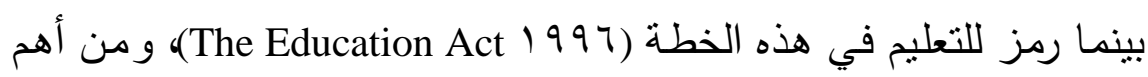

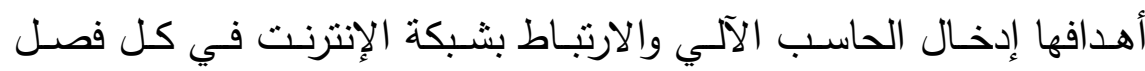

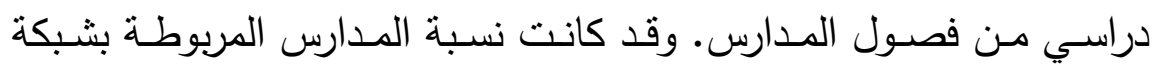

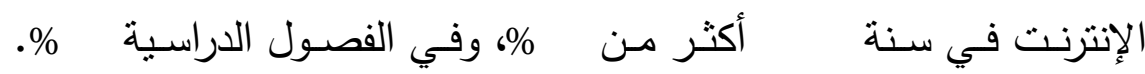


وتنسى المدارس الماليزيـة التي تطبق التقنية في هذه الفصـول " المدارس

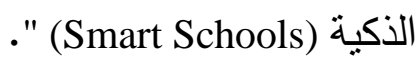

\section{خامسا: التجربة الأسترالية}

يوجد في استراليا عدد من وزارات التربية والتعليه، ففي كل ولايـة وزارة مستقلة، ولذا فالانخراط في مجال التقنية متفاوت من ولاية لأخرى، والتجربة ولته

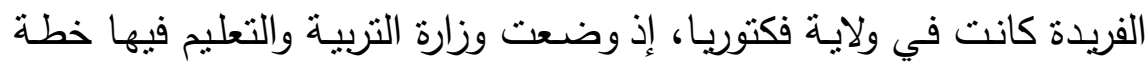

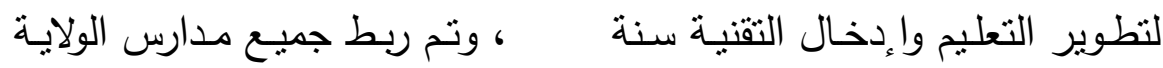

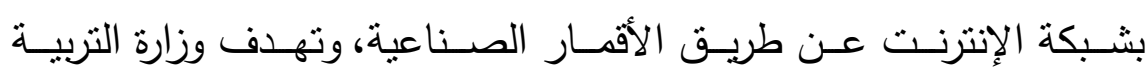
الأسترالية إلى تطبيق خطة تقنيات التعليم في جميع المدارس وذلك لتفعيل الذكاء المعرفي فيها، وضمن المؤشرات الآتية: - إمكانية استخدام أجهزة الحاسب الآلي والاستفادة من العديد من التطبيقات التهنئ

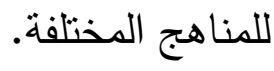
- الاستخدام الدائم والمؤهل لتقنيات التعليم ضمن البرامج المدرسية، وتطوير المهارات لغرض استخدام نلك التقنيات.

\section{سادسا: تجربة دولة الإمارات العربية المتحدة}

إن وزارة التربية والتعليم والثباب طبقت مشروع تطوير مناهج لتعليم مادة

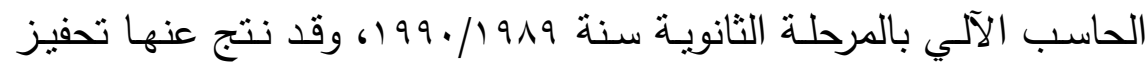
المعلمين والطلاب على تعلم الحاسب الآلي، فضـلا عن إدخاله في الإدارة وقد حُددت أهداف استخدام التقنيات التربويـة في التعليم للإمـارات في ضوء أحدث المفاهيم المطروحة ضمن العالم المعاصر ، ويتضـح ذلك في السياسة التعليمية للوزارة والخطط المستقبلية حتى سنة وهي كالآتي: 
- تطوير عمليتي التعليم والتعلم في المناهج، وأعداد الطلاب للتعامل بكفاءة مع عصر المعلومات باستخدام الحاسب الآلي وشبكات الاتصال المحلية ولية والدولية.

- تدريب المعلمينواءكسابهم الكفاءات المطلوبة لتنفيذ المناهج الجديدة.

\section{سابعا: تجرية التعليم الاكتروني المصرية}

تم تطبيقها من قبل وزارة التربية والتعليم المصرية، وذللك بإدخال التعليم الالكتروني على معظم المدارس الإعدادية في مصر بإضافة مواقع تعليمية

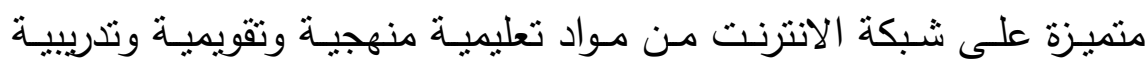

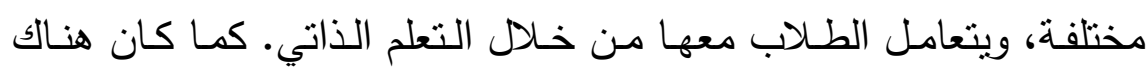
مساهمة لشبكة الجامعات المصرية بخدماتها التعليمية للجامعات والمدارس.

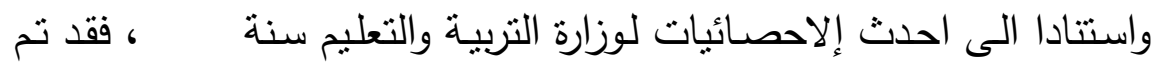

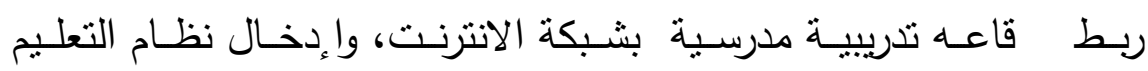
الالكتروني في مدرسـة إعداديـة، وتزويد كل مدرسـة بخمسـة أجهزة

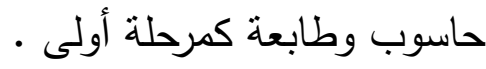

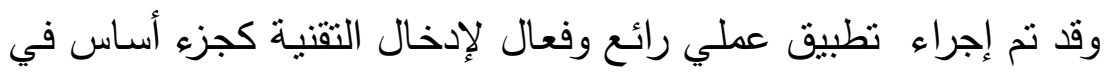

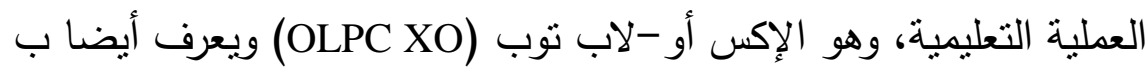
laptop)

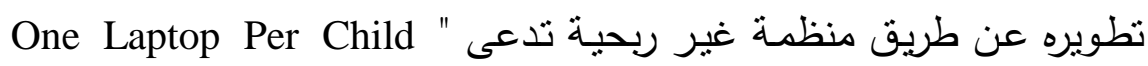
OLPC النامبة لبناء شبكات تعليم إلكترونية في المدارس الابتدائية في تلك الدول. ثامنا: تجرية الحاسوب المحمول - وزارة التربية والتعليم القلسطينية

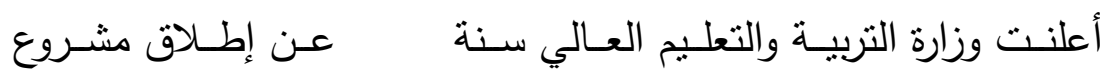
حاسوب محمول لكل طالب، بهدف تعزيز استخدام وسائل التقنيات التربوبية الحديثة، وتمكين الطلبة من الدخول إليها في سن مبكرة، وقد اسنطاعت 


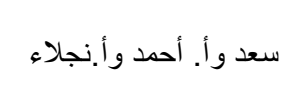

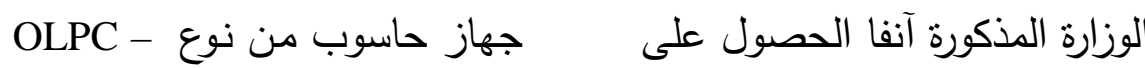
،American Task Force on Palestine Laptop XO

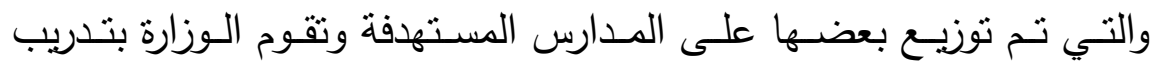

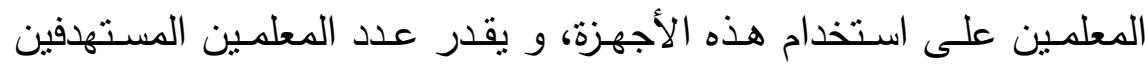

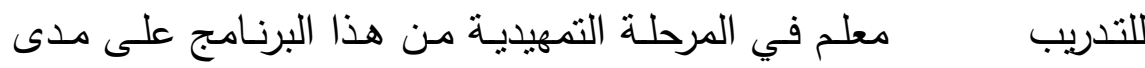

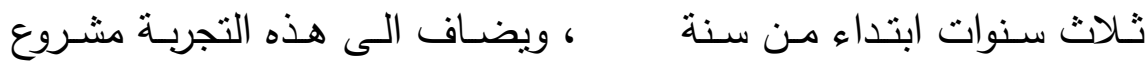

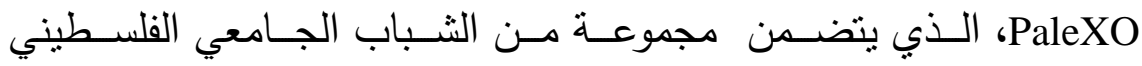
المتمرسين الذين تطوعوا لتوفير دعم تقني والكتروني، وعمل دورات تدريبية، وتوفير كتيبات تعليمية مختلفة تخدم هذا المشروع.

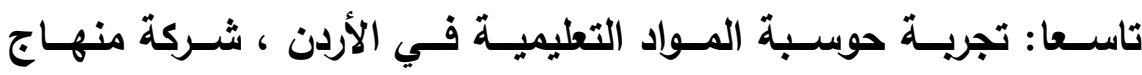

(Menhaj)

اهتمت بتطوير مواد تعليمية محوسبة ذات ارتباط كلي بالمنهج المعمول

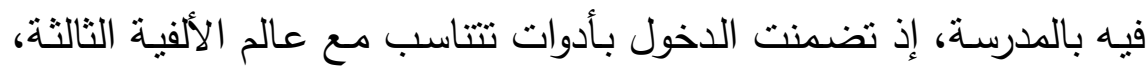

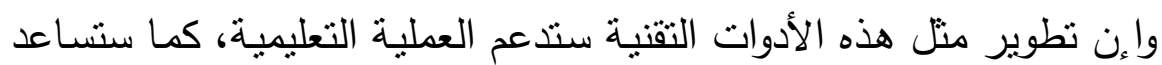

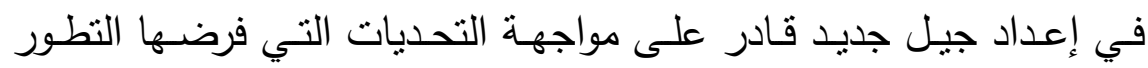
التقني، إذ تقدم شركة منهاج المواد الدراسية على أكثر من صعيد؛ لتهية لتلائم

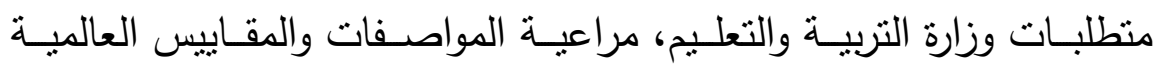

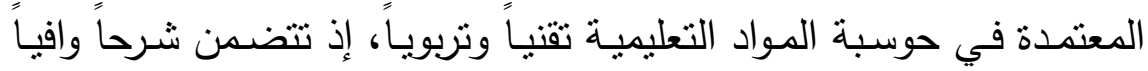

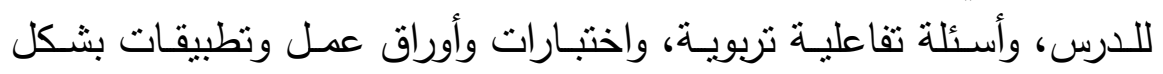

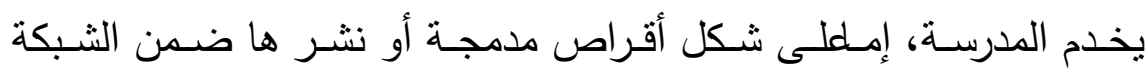
الاخلية أو العالمية للانترنت.

\section{الاستنتاجات والمقترحات}

توصل البحث الى مجموعة من الاستتناجات والمقترحات، وهي كالآتي: أولا: الاستنتاجات 
* تبين أن إدخال التقنيات المتطورة في المؤسسـة التعليمية باستخدام وسائل

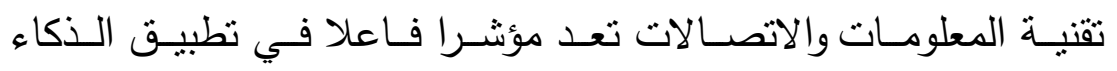
* اتضـح أن التعليم الالكتروني يمثل احد الاتجاهات الحديثة في منظومـة الذكاء المعرفي، فضلا عن تميز التهيم الالكتروني عن التقليدي واءسهامه الفهيه في هذه المنظومة. * إن ضـــان إيجـاد بيئـة تفاعليـة ثريـة بالتطبيقـات المعتمـدة على الثـبكة

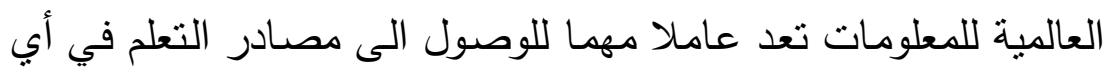

$$
\text { وقت ومكان. }
$$

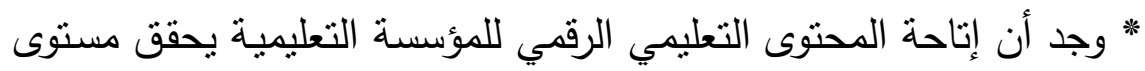
أعلى للتفاعل بين الذكاء المعرفي والتعليم الالكتروني.

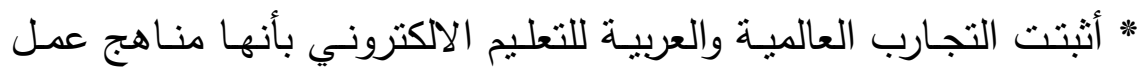
أساسية في تطبيق الذكاء المعرفي.

ثانيا: المقترحات • ثوفير دعم مـادي ومعنوي للمؤسسـة التعليمية والمتعلمين لضمان نجاح التحول إلى نظام التعليم الإلكتروني ووضعه وعلى دلى سلم الأولويات.

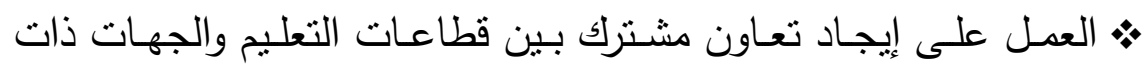

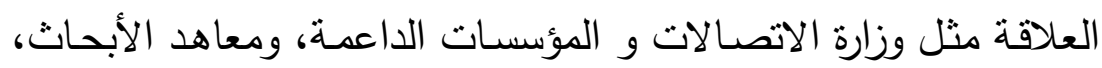

$$
\text { والقطاع الخاص......غيرها. }
$$

• بمالاعتمـاد على الطاقات البشرية المحلية، وضمان تتمية قدراتها وو عيها

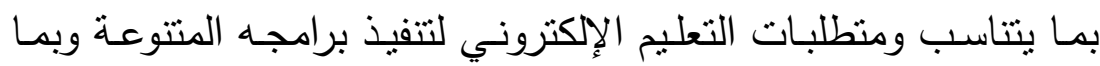
يعزز تطبيـق الذكاء المعرفي. الاسـتفادة مـن التجارب السـابقة وتبـادل

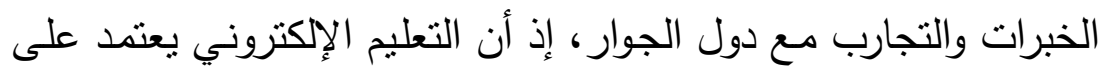




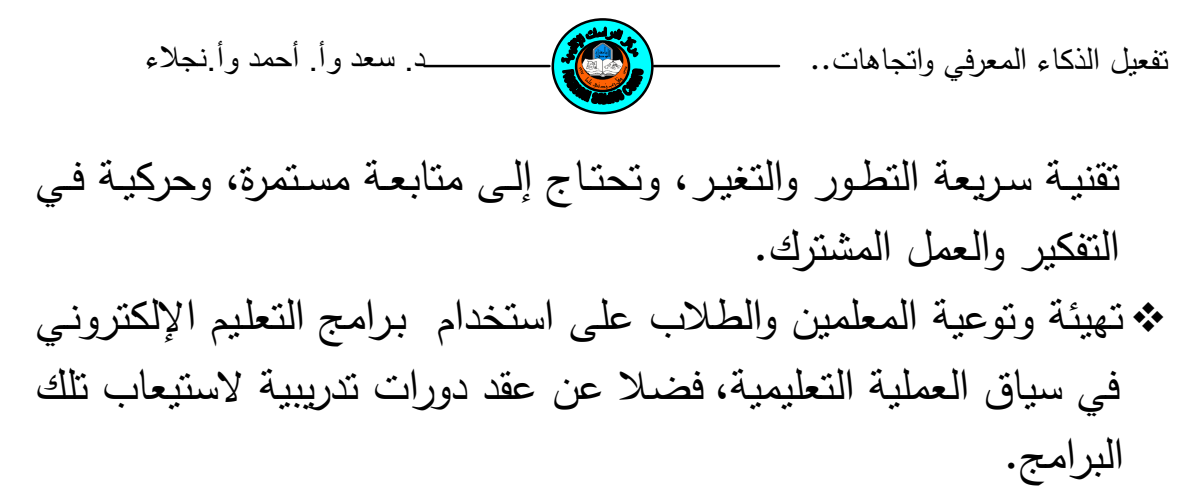

\title{
Activation of cognitive intelligence and trends in e-Learning for selected countries
}

\begin{abstract}
The global trend towards knowledge economies that depend on the basis of modern technologies and best use of economic resources led to a focus on knowledge investment to raise the level of welfare, as these technologies became a means of survival and a tool cannot be dispensed with under the open world depends on the competitiveness ability. The research aims to identify the contents of the Cognitive Intelligence and the most important trends in elearning in the countries of the sample, and will adopt descriptive analysis approach for the style of trends in the Arab and international experiences from their original sources, as well as
\end{abstract}


research articles, and Arabic and foreign books, which will be a set of conclusions and proposals.

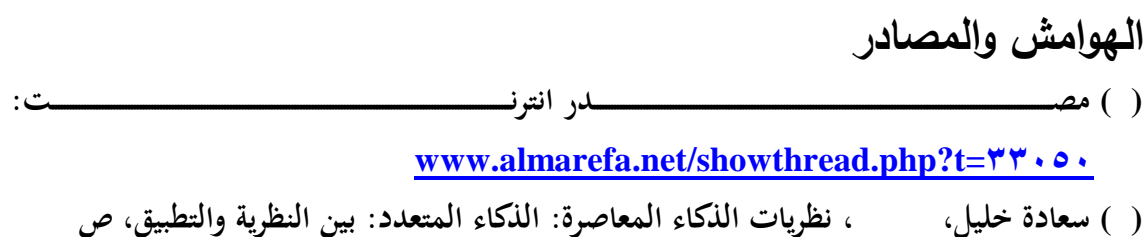

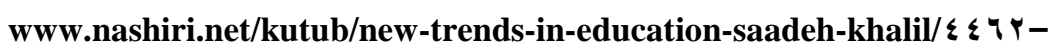

$r \cdot 1 \cdot-0-1 \cdot-r \mu-0,-\varepsilon r . h t m l$

( ) محمد بن صـنت بن صالح الحربي، اللقاء الأول لمشرفي التعليم الإلكتروني القصيم

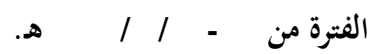

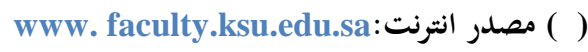

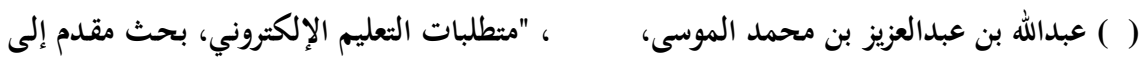

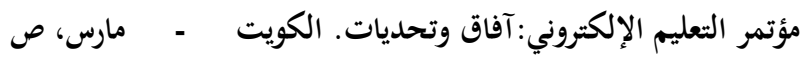

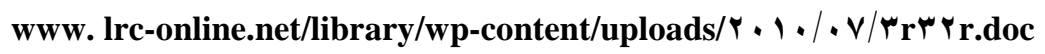

Www.besheir.Moloum.org/t I Y-topic ( ) مصدر انترنت

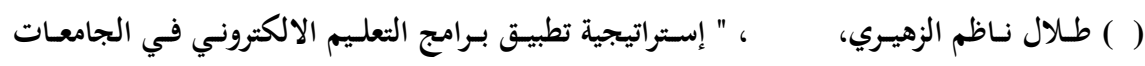

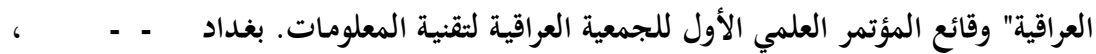

. - ص

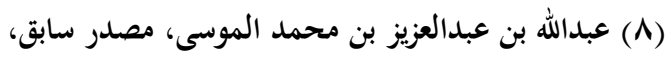

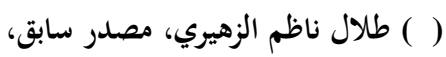

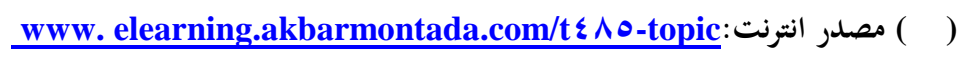

: www.kku.edu.sa/ELearning/ELearning/Default.aspp ( ) مصدر انترنت ( )

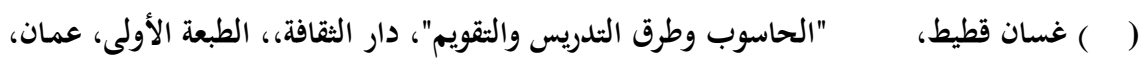

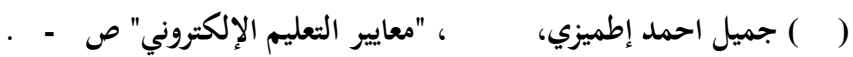

doc معايير \%ww.abegs.org/sites/Upload/.../ التعلير 


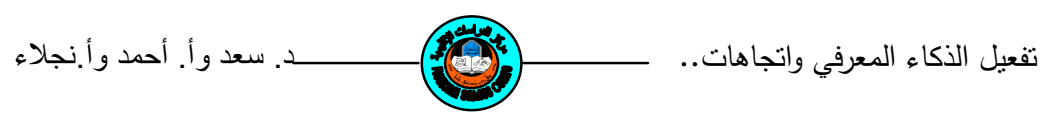

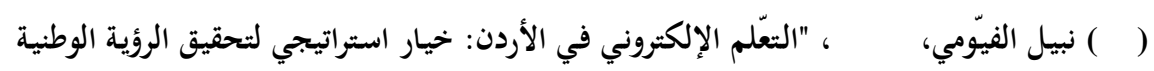

$$
\begin{aligned}
& \text { التحديات، الإنجازات، وآفاق المستقبل" وزارة الاتصالات و تقنية المعلومات - الأردن، ص ل ل }
\end{aligned}
$$

